\title{
Preparation and unequivocal identification of the regioisomers of nitrocatechol
}

\section{monobenzyl ether}

\author{
Cristiano Bolchi, ${ }^{*}$ Francesco Bavo, and Marco Pallavicini \\ Dipartimento di Scienze Farmaceutiche, Università degli Studi di Milano, via Mangiagalli 25, I- \\ 20133, Milano, Italia
}

E-mail: cristiano.bolchi@unimi.i

\begin{abstract}
The four positional isomers of nitrocatechol monobenzyl ether were prepared as intermediates to nitrobenzodioxanes directly from 2-benzyloxyphenol or, through two-four steps, from catechol. These preparations addressed the issue of the certain identification of the nitration products prescinding from chemical correlation to the synthetic precursors because the positional isomers are very similar for some properties and analytical data available from literature are largely incomplete and not conclusive. The here provided NMR, DSC and acidity data unequivocally distinguish each nitrocatechol monobenzyl ether from its regioisomers.
\end{abstract}

Keywords: nitrocatechol, cerium ammonium nitrate (CAN), catechol monobenzyl ether, 2benzyloxyphenol, 2-benzyloxy-4,6-dinitrophenol, regioisomer.

\section{INTRODUCTION}

Desymmetrized dihydroxyphenols and, among these, catechol monoethers are very important starting materials. Their ortho, meta and para substituted derivatives have been used as key intermediates in the synthesis of the 1,4-benzodioxane substructure of neuronal nicotinic agonists ${ }^{1}$ 
and of $\alpha$-adrenergic antagonists ${ }^{2,3}$ or, more generally, of the phenoxy portion of these latter compounds. ${ }^{4,5}$ Often commercially avalaible, catechol monoethers are highly reactive substrates to elctrophilic aromatic substitutions, owing their reactivity to the two electron donating groups. These substitutions, however, proceed with only moderate regiocontrol because all the four unsubstituted ring carbons are nucleophilic sites. Furthermore, if electron donating, the incoming substituent makes the aromatic system even more inclined to undergo further substitutions and therefore it is difficult to stop the process after a single substitution. Anyway, this drawback does not affect nitration, which can be easily stopped at mononitration by regulating the reaction temperature. Besides giving access to a number of reduced derivatives, a further advantage of catechol monoethers nitration is that the nitro group exerts a specific effect on the two oxy substituents: it exalts the acidity and thus facilitates the etherification of the ortho or para positioned $\mathrm{OH}$ and, on the other hand, it makes the ortho or para positioned OR susceptible of nucleophilic substitution by hydroxide ion. Such a dual effect of the nitro group confers synthetic versatility to the regioisomeric nitro derivatives of catechol monoethers such as guaiacol and 2-benzyloxyphenol. In the case of these latter positional isomers (1a-d), an additional advantage is provided by the easy removal, if necessary, of benzyl by hydrogenolysis.

In view of the synthesis of the regioisomeric nitrobenzodioxanes $\mathbf{2 a - d}$ as bioisosteres of the pyridodioxanes 3a-d, previously reported nicotinic agonists, ${ }^{6}$ we needed the four regioisomers 1a-d (Scheme 1). An overview of the literature methods shows that most syntheses of the single positional isomers of $\mathbf{1}$ are quite laborious (Scheme 2). ${ }^{7-15}$ The reported overall yields are generally very modest (about 20\%), apart those of 1a from catechol monobenzyl ether III (43\%) ${ }^{15}$ and of $\mathbf{1 b}$ from 1,3 benzodioxol I (about 50\%). ${ }^{7,8}$

Furthermore, some of these procedures date back to the sixties and the eighties and even today not all the regioisomers are adequately provided with a number of accurate physical and spectral data so as to allow an immediate and incontrovertible identification distinguishing, in particular, between 1a and 1d and between 1b and 1c. Indeed, the melting point of $\mathbf{1 a}$ is unknown and its ${ }^{1} \mathrm{H}$ NMR 
spectrum has been only roughly described, ${ }^{15,16}$ while, for $\mathbf{1 d}$, the melting point is reported, ${ }^{14}$ but not the ${ }^{1} \mathrm{H}$ NMR spectrum, which should be very similar to that of $\mathbf{1 a}$ in the multiplicity pattern and chemical shifts of the three vicinal hydrogens of the phenol ring. On the other hand, $\mathbf{1 b}$ and $\mathbf{1 c}$, which have almost identical melting points, ${ }^{8,9,14}$ are hardly distinguishable from each other on the basis of the ${ }^{1} \mathrm{H}$ NMR spectrum descriptions reported in literature. ${ }^{8,17}$

\section{RESULTS AND DISCUSSION}

We focused on nitration of III and on separation and analytical characterization of the nitration products. As all the four nitrable positions of III are reactive to electrophilic substitution, we oriented to mild nitration conditions such as treatment of a dichloromethane solution of III with $\mathrm{NaNO}_{3}$ and diluted sulfuric acid at low temperature $\left(-10^{\circ} \mathrm{C}\right)$. After three hours under these conditions, III was no more detectable by TLC and chromatography of the reaction mixture separated three products that, in the order of elution, were recognized by ${ }^{1} \mathrm{H}$ NMR analysis as resulting from mono-nitration in ortho to $\mathrm{OH}$ or $\mathrm{OBn}$, mono-nitration in para to $\mathrm{OH}$ or $\mathrm{OBn}$ and dinitration respectively (Scheme 3).

Assignment of 1a instead of 1d structure to the first eluted ortho-nitrated product ( $35 \%$ yield) on the only basis of ${ }^{13} \mathrm{C}$ NMR and ${ }^{1} \mathrm{H}$ NMR spectrum was questionable, although the latter spectrum was consistent with that reported for $\mathbf{1 a}$ in a patent, ${ }^{15,16}$ as very similar NMR spectra can be expected for 1d. On the other hand, also the melting point $\left(98^{\circ} \mathrm{C}\right)$, higher than that reported for $1 \mathbf{d}$, ${ }^{14}$ was not resolutory because literature does not provide the melting point of $\mathbf{1 a}$. The identification of the product as 1a was therefore supported by NOESY spectrum that showed interaction between the benzylic protons and the phenol H-3, and definitively confirmed by characterizing $\mathbf{1 d}$. This was synthesized as illustrated in Scheme 2 according to Augstein et al. ${ }^{14}$ The literature low melting point of $1 \mathbf{d}\left(44-52{ }^{\circ} \mathrm{C}\right),{ }^{14}$ much lower than that we had found for $\mathbf{1 a}$, was confirmed by the viscous oil consistency of our product. The ${ }^{1} \mathrm{H}$ NMR and the ${ }^{13} \mathrm{C}$ NMR spectra, as expected, showed patterns of signals and multiplicity very similar to those of $\mathbf{1 a}$ with chemical shift differences which, yes, allow 
to clearly distinguish 1a and 1d from each other but only a posteriori, that is by comparing the respectively acquired spectra (Figure 1A, Table I).

Once identified 1a, an analogous problem was addressed by the identification of the second eluted para-nitrated product because the only reported analytical data of $\mathbf{1 b}$ and $\mathbf{1 c}$, namely melting points and ${ }^{1} \mathrm{H}$ NMR spectrum descriptions, are virtually identical. Again, any doubt was removed by unequivocally synthesizing $\mathbf{1 b}$ from 4-nitrocatechol through selective benzylation of the more acidic $\mathrm{OH}$, para positioned to the nitro substituent (Scheme 2). As shown in Table I and in Figure 1B, the ${ }^{1} \mathrm{H}$ NMR spectra of $\mathbf{1 b}$ and $\mathbf{1 c}$ are indeed nearly identical and only the comparison of the ${ }^{13} \mathrm{C}$ NMR spectra and, in particular, of the chemical shifts of the three unsubstituted carbons of phenol ring allows 1c to be certainly distinguished from $\mathbf{1 b}$. On the basis of such a comparison, we could concluded that the second eluted product was 1 c $(30 \%$ yield $)$ and that the $o-p$ orientation by $\mathrm{OH}$ prevails over that by OBn resulting in the formation of $\mathbf{1 a}$ and $\mathbf{1 c}$ instead of $\mathbf{1 d}$ and $\mathbf{1 b}$.

To validate such an assignment we also verified the expected higher acidity of 1a and 1c compared to that of $\mathbf{1 d}$ and $\mathbf{1 b}$ by measuring the $\mathrm{pH}$ of equimolar aqueous solutions of the respective potassium salts. In fact, we found that both the potassium salts of 1a and 1c are sensibly less basic $(8.57$ and $8.44 \mathrm{pH})$ than the potassium salts of $\mathbf{1 d}$ and $\mathbf{1 b}(9.18$ and $9.42 \mathrm{pH})$. Interestingly, the $\mathrm{pH}$ values of the solutions of the potassium salts of $1 \mathbf{a}$ and $1 \mathbf{c}$ indicated also that, between the two phenols, 1c is little more acidic than 1a and this can be explained by a strong intramolecular hydrogen bond between the ortho positioned $\mathrm{OH}$ and $\mathrm{NO}_{2}$ in $1 \mathbf{a} .{ }^{18}$ Furthermore, the basicity ranking we found for the potassium salts of $\mathbf{1} \mathbf{a}-\mathbf{1 d}(\mathbf{1} \mathbf{b}>\mathbf{1 d}>>\mathbf{1 a}>\mathbf{1 c})$ corresponds, if overturned, to the acidity order of mono-nitrated guaiacols, that is 2-methoxy-4-nitro- $>2$-methoxy-6-nitro- $>>2$-methoxy-3-nitro- $>$ 2methoxy-5-nitrophenol. ${ }^{19}$ This indicates that, as expected, nitrocatechol mono benzyl ethers and monomethyl ethers show parallel acidity rankings. The third eluted product was identified as 2benzyloxy-4,6-dinitrophenol (1e) by NMR and HRMS analysis and it was excluded that dinitration was occurred at 3 and 5 positions on account of the previous identification of the mono-nitrated products as $1 \mathbf{a}$ and $\mathbf{1 c}$. Its yield amounted to $12 \%$. 
Interest in having all four regioisomers 1a-1d prompted us to consider the nitration of III under alternative conditions, such as treatment with ceric ammonium nitrate (CAN) in acetonitrile, which is reported to give all the four mono-nitrated positional isomers, each with $10-30 \%$ yield, when applied to catechol monomethyl ether. ${ }^{20}$ On the contrary, nitration of III with CAN in acetonitrile and subsequent chromatography exclusively provided $\mathbf{1 a}$ and $\mathbf{1 c}$ and in very high yield (Scheme 4). Under such conditions, dinitration did not occur and $\mathbf{1 b}$ and $\mathbf{1 d}$ were not formed in an appreciable amount.

\section{CONCLUSIONS}

In summary, we prepared the four positional isomers of nitrocatechol monobenzyl ether: the two isomers $o$ - and $p$-nitrated to $\mathrm{OH}$ by nitration of 2-benzyloxyphenol, preferably with $\mathrm{CAN}$ as a nitrating agent in acetonitrile, and the two isomers $o$ - and $p$-nitrated to $\mathrm{OBn}$ from catechol through four- and two-steps syntheses respectively. It was soon realized that the main challenge was the nitrated products unequivocal identification, which was impossible on the basis of the preparation of a single isomer because of the incomplete and sometimes rough analytical data reported in literature. Therefore, the four nitrocatechol monobenzyl ethers were accurately characterized for $\mathrm{H}$ and ${ }^{13} \mathrm{C}$ NMR spectral data, DSC traces and acidity properties so as to allow, from then on, their incontrovertible and independent identification prescinding from any chemical correlation to the synthetic precursors.

\section{EXPERIMENTAL}

Nitration of III with sodium nitrate and sulphuric acid: Sodium nitrate $(2.30 \mathrm{~g}, 27,05 \mathrm{mmol}), 3$ M sulfuric acid $(31 \mathrm{~mL})$ and sodium nitrite $(10 \mathrm{mg})$ were sequentially added to a stirred solution of 2-benzyloxyphenol (5 g, $25.0 \mathrm{mmol})$ in DCM $(40 \mathrm{~mL})$ cooled at $-10^{\circ} \mathrm{C}$. The reaction mixture was stirred for three hours at the same temperature, then diluted with DCM and washed with water. The organic phase was concentrated and purified on silica gel (cyclohexane/ethyl acetate 8/2) to give, in 
sequence, 1a (2.15 g, 35\%) and $1 \mathrm{c}(1.84 \mathrm{~g}, 30 \%)$ as yellow solids and $1 \mathrm{e}(0.87 \mathrm{~g}, 12 \%)$ as a brown solid. Analytical data for $\mathbf{1 a}, \mathbf{1 c}$ and $\mathbf{1 e}$ are reported in Table I and in the Supporting Information.

Nitration of III with CAN: A solution of $\left(\mathrm{NH}_{4}\right)_{2} \mathrm{Ce}\left(\mathrm{NO}_{3}\right)_{6}(10 \mathrm{~g}, 18.2 \mathrm{mmol})$ in acetonitrile (60 $\mathrm{mL}$ ) was added dropwise to a stirred solution of 2-benzyloxyphenol (5 g, $25.0 \mathrm{mmol})$ in acetonitrile $(40 \mathrm{~mL})$ cooled at $-5{ }^{\circ} \mathrm{C}$. The reaction mixture was stirred for $3 \mathrm{~h}$ at $0{ }^{\circ} \mathrm{C}$ and then diluted with water and extracted with ethyl acetate. The organic phase was concentrated and the resulting residue was purified on silica gel (cyclohexane/ethyl acetate $8 / 2)$ to give, in sequence, $1 \mathrm{a}(3.56 \mathrm{~g}, 58.1 \%)$ and $1 \mathrm{c}$ $(2.08 \mathrm{~g}, 34.0 \%)$ as yellow solids. Analytical data for $\mathbf{1 a}$ and $\mathbf{1 c}$ are reported in Table I and in the Supporting Information.

2-Benzyloxy-5-nitrophenol (1b): A solution of 4-nitrocatechol (5 g, $32.2 \mathrm{mmol})$ in DMF (25 mL) was added dropwise to a suspension of $\mathrm{NaH}(774 \mathrm{mg}, 32.2 \mathrm{mmol})$ in $\mathrm{DMF}(50 \mathrm{~mL})$ cooled at $-10{ }^{\circ} \mathrm{C}$. The reaction mixture was stirred for $1 \mathrm{~h}$ at room temperature. After cooling at $-10{ }^{\circ} \mathrm{C}$, a solution of benzyl bromide $(3.8 \mathrm{~mL}, 32.2 \mathrm{mmol})$ in DMF $(20 \mathrm{~mL})$ was slowly added over a period of $30 \mathrm{~min}$. After $16 \mathrm{~h}$ at room temperature, the mixture was diluted with ethyl ether and washed with $1 \mathrm{~N} \mathrm{HCl}$. The organic phase was concentrated and the resultant residue purified on silica gel (cyclohexane/DCM 8/2) to give $\mathbf{1 b}(6.32 \mathrm{~g}, 80 \%)$ as a light yellow solid. The analytical data are reported in Table I and in the Supplementary material.

\section{REFERENCES}

1. Bolchi, C.; Gotti, C.; Binda, M.; Fumagalli, L.; Pucci, L.; Pistillo, F.; Vistoli, G.; Valoti, E.; Pallavicini, M. J. Med. Chem. 2011, 54, 7588-7601.

2. Valoti, E.; Pallavicini, M,; Villa, L.; Pezzetta, D. J. Org. Chem. 2001, 66, 1018-1025.

3. Pallavicini, M.; Budriesi, R.; Fumagalli, L.; Ioan, P.; Chiarini, A.; Bolchi, C.; Ugenti, M. P.; Colleoni, S.; Gobbi, M.; Valoti, E. J. Med. Chem. 2006, 49, 7140-7149. 
4. Pallavicini, M.; Fumagalli, L.; Gobbi, M.; Bolchi, C.; Colleoni, S.; Moroni, B.; Pedretti, A.; Rusconi, C.; Vistoli, G.; Valoti, E. Eur. J. Med. Chem. 2006, 41, 1025-1040.

5. Fumagalli, L.; Pallavicini, M.; Budriesi, R.; Gobbi, M.; Straniero, V.; Zagami, M.; Chiodini, G.; Bolchi, C.; Chiarini, A.; Micucci, M.; Valoti, E. Eur. J. Med. Chem. 2012, 58, 184-191.

6. Bolchi, C.; Bavo, F.; Gotti, C.; Fumagalli, L.; Fasoli, F.; Binda, M.; Mucchietto, V.; Sciaccaluga, M.; Plutino, S.; Fucile, S.; Pallavicini, M. Eur. J. Med. Chem. 2017, 125, $1132-$ 1144.

7. Alam, M. I.; Alam, M. A.; Alam, O.; Nargotra, A.; Taneja, S. C.; Koul, S. Eur. J. Med. Chem. 2016, 114, 209-219.

8. Kobayashi, S.; Okimoto, K.; Imakura, Y. Chem. Pharm. Bull. 1982, 30, 1567-1573.

9. Page, D. F.; Clinton, R. O. J. Org. Chem. 1962, 27, 218-226.

10. Cambie, R. C.; Clark, G. R.; Coombe, S. L.; Coulson, S. A.; Rutledge, P. S.; Woodgate, P. D. J. Organomet. Chem. 1996, 507, 1-21.

11. Astles, P. C.; Brown, T. J.; Cox, P.; Halley, F.; Lockey, P. M.; McCarthy, C.; McLay, I. M.; Majid, T. N.; Morley, A. D.; Porter, B.; Ratcliffe, A. J.; Walsh, R. J. A. Bioorg. Med. Chem. Lett. 1997, 7, 907-912.

12. Bredereck, H.; Heck, H. Chem. Ber. 1958, 91, 1314-1318.

13. Barton, D. H. R.; Linnell, W. H.; Senior, N. Quart. J. Pharm. Pharmacol. 1945, 18, 41-47.

14. Augstein, J.; Green, S. M.; Monro, A. M.; Potter, G. W. H.; Worthing, C. R.; Wrigley, T. I. J. Med. Chem. 1965, 8, 446-456.

15. Widdowson, K. L.; Veber, D. F.; Jurewicz, A. J.; Hertzberg, R. P.; Rutledge, M. C. Jr. US6262113 B1, 2001.

16. The ${ }^{1} \mathrm{H}$ NMR spectrum of $1 \mathbf{a}$ in ref. 15 is registered in $\mathrm{CD}_{3} \mathrm{COCD}_{3}$, but we found the there reported chemical shifts when we registered the spectrum of $\mathbf{1 a}$ in $\mathrm{CDCl}_{3}$ and not in $\mathrm{CD}_{3} \mathrm{COCD}_{3}$.

17. Wang, Z. Q.; Staab, A. J.; Seekamp, C. K.; Luke, G. P. WO2008118935 A1, 2008. 
18. Baitinger, W. F.; Schleyer, R. P.; Murty, T. S. S. R.; Robinson, L. Tetrahedron 1964, 20, $1635-1647$.

19. Sunkel, J.; Staude, H. Ber. Bunsenges. Phys. Chem. 1968, 72, 567-573.

20. Chaudhuri, K.; Chawla, H. M. Indian J. Chem. 1985, 24B, 1277-1279. 


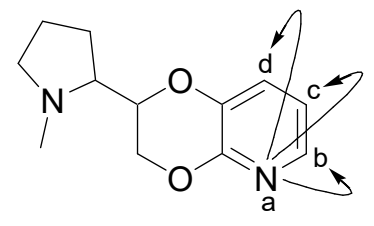

3a-d

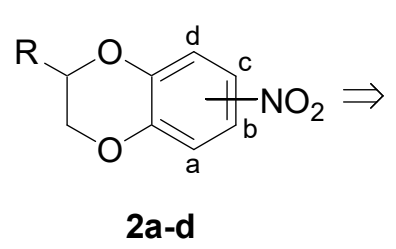

2a-d

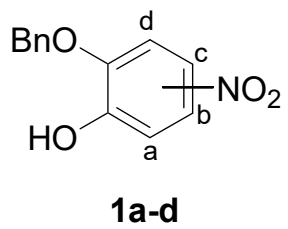

Scheme 1. Regioisomeric mononitrated 2-benzyloxyphenols 1a-d as precursors of nitrobenzodioxanes 2a-d, conceived as bioisosteres of pyridodioxanes 3a-d.

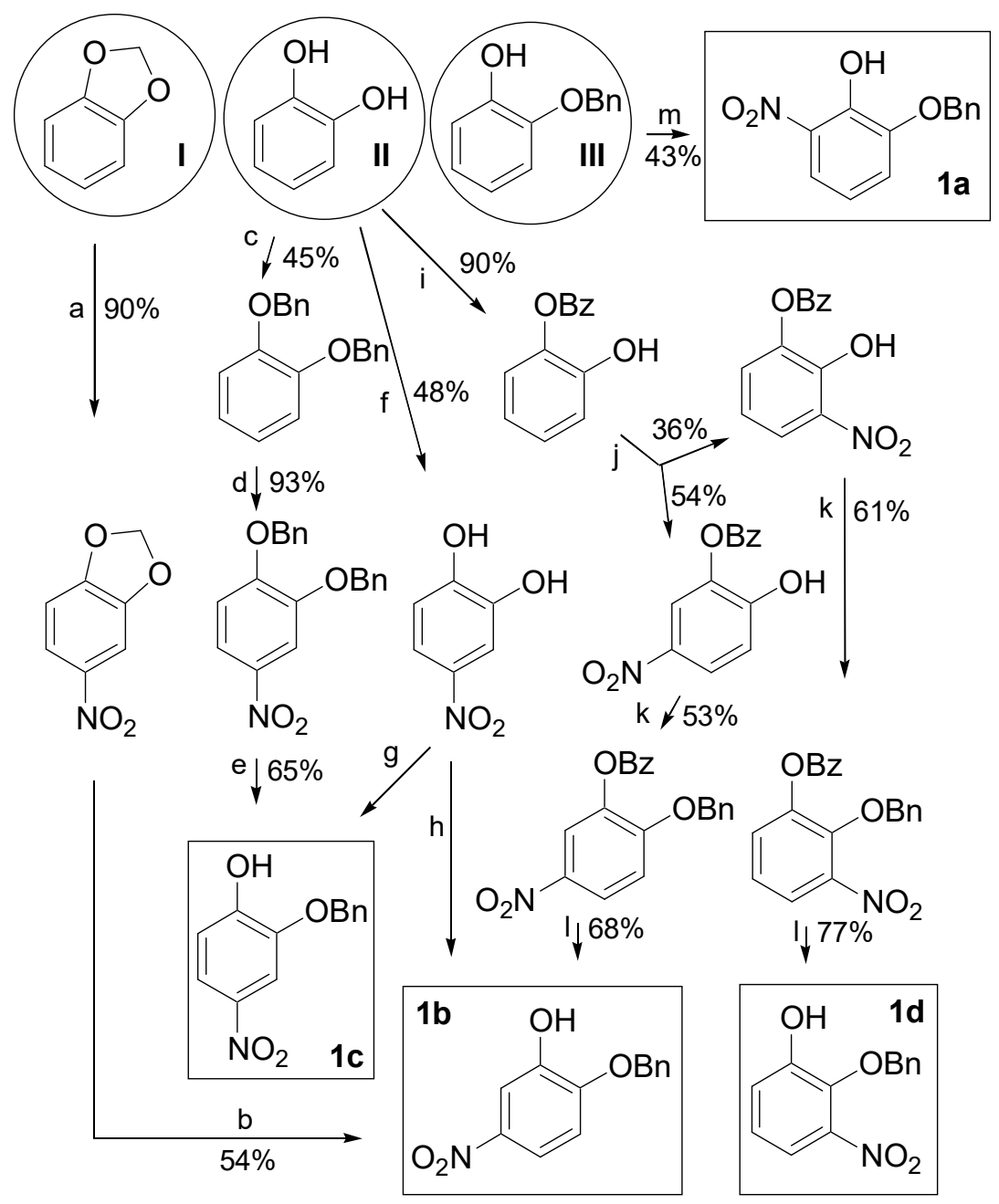

Scheme 2. Mononitrated 2-benzyloxyphenols from 1,3-benzodioxol, catechol and 2benzyloxyphenol: (a) $\mathrm{HNO}_{3}, \mathrm{H}_{2} \mathrm{SO}_{4}, \mathrm{AcOH},-5{ }^{\circ} \mathrm{C} ;{ }^{7}$ (b) $\mathrm{BnONa}, \mathrm{BnOH}, \mathrm{DMSO}, 155{ }^{\circ} \mathrm{C} ;{ }^{8}$ (c) $\mathrm{BnCl}$, $\mathrm{Na}_{2} \mathrm{CO}_{3}$, KI, EtOH, $\mathrm{H}_{2} \mathrm{O}$, reflux; ${ }^{9}$ (d) $\mathrm{HNO}_{3}, \mathrm{AcOH}, \mathrm{rt} ;{ }^{9}$ (e) $\mathrm{KOH}, \mathrm{H}_{2} \mathrm{O}$, 2-methoxyethanol, reflux; ${ }^{9}$ (f) $\mathrm{HNO}_{3}, \mathrm{Et}_{2} \mathrm{O}, \mathrm{rt} ;{ }^{10}$ (g) BnBr, NaH (2 eq), DMF, rt; ${ }^{11}$ (h) BnBr, NaH (1 eq), DMF, rt; ${ }^{11}$ (i) BzCl, $\mathrm{KOH}, \mathrm{H}_{2} \mathrm{O}, \mathrm{rt} ;{ }^{12}$ (j) $\mathrm{HNO}_{3}, \mathrm{AcOH}, \mathrm{rt}^{13}$ (k) $\mathrm{BnBr}, \mathrm{MgSO}_{4}, \mathrm{~K}_{2} \mathrm{CO}_{3}$, acetone, reflux; ${ }^{14}$ (l) $\mathrm{KOH}, \mathrm{EtOH}$, reflux; ${ }^{14}(\mathrm{~m}) \mathrm{NaNO}_{3}, \mathrm{NaNO}_{2}, \mathrm{H}_{2} \mathrm{SO}_{4}, \mathrm{DCM}$, rt. $^{15}$ 


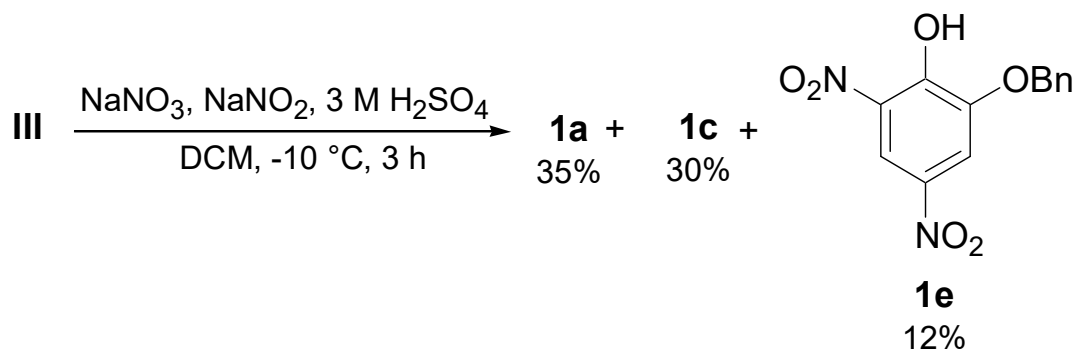

Scheme 3. Nitration products from catechol monobenzyl ether treated with $\mathrm{NaNO}_{3}$ and diluted $\mathrm{H}_{2} \mathrm{SO}_{4}$ at low temperature.

$$
\text { III } \underset{\left(\mathrm{NH}_{4}\right)_{2} \mathrm{Ce}\left(\mathrm{NO}_{3}\right)_{6}, \mathrm{CH}_{3} \mathrm{CN}}{0^{\circ} \mathrm{C}, 3 \mathrm{~h}} \underset{58 \%}{\mathbf{1 a}}+\underset{34 \%}{1 \mathbf{c}}
$$

Scheme 4. Nitration products from catechol monobenzyl ether treated with CAN in acetonitrile
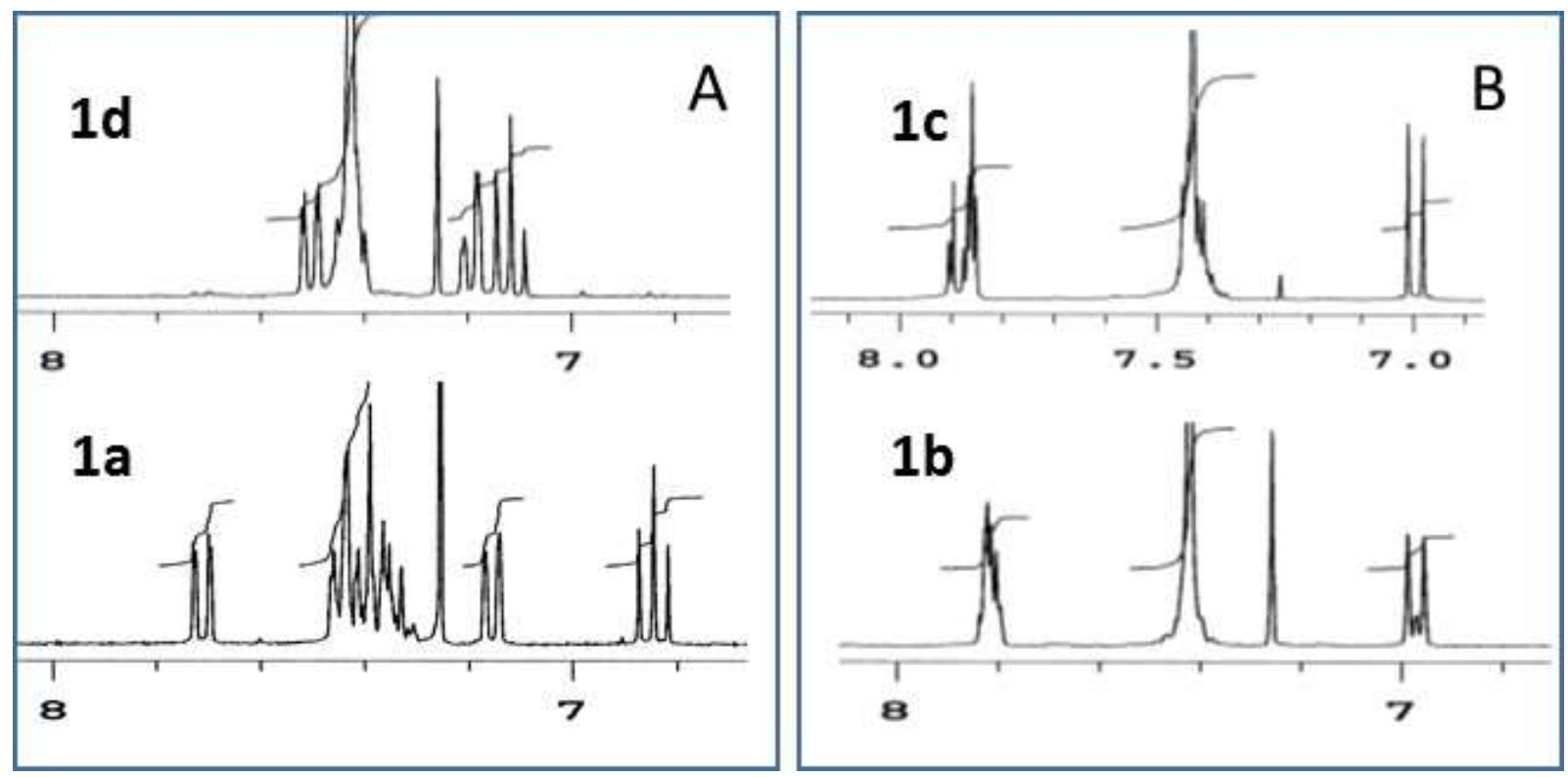

Figure 1. Aromatic region of the ${ }^{1} \mathrm{H}$ NMR spectra of 1a-1d. (A) The three adjacent hydrogens of the phenol ring of 1a and 1d give analogous sequence of signals: dd, $\mathrm{dd}$ and $\mathrm{t}$ (from low field to high field). (B) In the aromatic region, the spectra of $\mathbf{1 b}$ and $\mathbf{1 c}$ are nearly identical. 
Table I. Melting points and ${ }^{1} \mathrm{H}$ and ${ }^{13} \mathrm{C}$ NMR chemical shifts of the four mono-nitrated regioisomers of 2-benzyloxyphenol (1a-1d) and of 2-benzyloxy-4,6-dinitrophenol (1e) and $\mathrm{pH}$ of the aqueous solutions of the potassium salts of $\mathbf{1 a - 1 d}$.

\begin{tabular}{|c|c|c|c|c|c|c|c|}
\hline \multirow[t]{2}{*}{ Compd } & \multirow{2}{*}{$\begin{array}{l}\mathrm{Mp}^{\mathrm{a}} \\
\left({ }^{\circ} \mathrm{C}\right)\end{array}$} & \multicolumn{4}{|c|}{${ }^{1} \mathrm{H}$ NMR: chemical shifts of protons of phenol ring ${ }^{b}$} & \multirow{2}{*}{$\begin{array}{l}{ }^{13} \mathrm{C} \text { NMR: chemical } \\
\text { shifts of unsubstituted } \\
\text { carbons of phenol ring }{ }^{b}\end{array}$} & \multirow{2}{*}{$\begin{array}{c}\mathrm{pH} \text { of K salt } \\
(3.5 \mathrm{mM} \text { in } \\
\text { water }) \text { at } 25^{\circ} \mathrm{C}\end{array}$} \\
\hline & & $\mathrm{H}-\mathrm{C} 3$ & $\mathrm{H}-\mathrm{C} 4$ & $\mathrm{H}-\mathrm{C} 5$ & H-C6 & & \\
\hline 1a & 97.77 & $\begin{array}{c}7.16 \\
(\mathrm{dd}, 8.2,1.2)\end{array}$ & $\begin{array}{c}6.85 \\
(t, 8.2) \\
\end{array}$ & $\begin{array}{c}7.72 \\
(\mathrm{dd}, 8.2,1.2)\end{array}$ & & $116.72,118.81,120.67$ & 8.57 \\
\hline 1d & $\begin{array}{c}\text { viscous } \\
\text { oil } \\
\end{array}$ & & $\begin{array}{c}7.49 \\
(\mathrm{dd}, 8.2,1.8) \\
\end{array}$ & $\begin{array}{c}7.12 \\
(\mathrm{t}, 8.2) \\
\end{array}$ & $\begin{array}{c}7.19 \\
(\mathrm{dd}, 8.2,1.8) \\
\end{array}$ & $116.87,120.89,124.52$ & 9.18 \\
\hline 1c & 83.07 & $\begin{array}{c}7.87 \\
(\mathrm{~d}, 2.4) \\
\end{array}$ & & $\begin{array}{c}7.90 \\
(\mathrm{dd}, 8.8,2.4) \\
\end{array}$ & $\begin{array}{c}7.01 \\
(\mathrm{~d}, 8.8)\end{array}$ & $107.67,114.20,118.85$ & 8.44 \\
\hline $\mathbf{1 b}$ & 83.76 & $6.97(\mathrm{~d}, 9.9)$ & $7.81(\mathrm{~m})$ & & $7.81(\mathrm{~m})$ & $110.34,110.89,116.81$ & 9.42 \\
\hline 1e & $-{ }^{c}$ & $7.29(\mathrm{~d}, 2.9)$ & & $8.43(\mathrm{~d}, 2.9)$ & & $106.57,119.38$ & nd \\
\hline
\end{tabular}

${ }^{\text {a }}$ The melting points were determined by DSC analysis and the melting peak maximum is reported for each compound. ${ }^{\mathrm{b}}$ The spectra were registered in $\mathrm{CDCl}_{3}$ excepting those of $1 \mathrm{e}$, which were registered in DMSO- $d_{6} \cdot{ }^{\mathrm{c}}$ Decomposition $>200^{\circ} \mathrm{C}$. 